\title{
Delivery of Huge Bladder Stone in a Thirty-Five-Year-Old Man
}

\author{
Alireza Farshi ${ }^{1}$; Reza Sari Motlagh ${ }^{1, *}$; Rasole Jafari Arismani ${ }^{1}$ \\ ${ }^{1}$ Department of Urology, Imam Reza Hospital, Tabriz University of Medical Sciences, Tabriz, IR Iran \\ *Corresponding author: Reza Sari Motlagh, Department of Urology, Imam Reza Hospital, Tabriz University of Medical Sciences, Tabriz, IR Iran. Tel: +98-411545105423, E-mail: motlagh. \\ reza.dr@gmail.com
}

Received: May 23, 2014; Revised: July 16, 2014; Accepted: August 6, 2014

\begin{abstract}
Introduction: Bladder stone is the most common form of lower urinary tract stones and constitutes $5 \%$ of all urinary tract stones. The giant bladder stones are very rare and our report was the first one in Iran and in the world.

Case Presentation: The patient was a 35-year-old man who was referred to our urology clinic with the lower urinary tract symptoms. Irritative symptoms were dominant without obstructive symptoms. During a physical examination, hard mass was palpated in suprapubic area. On ultrasonography, a huge stone with 110-mm diameter was revealed in the bladder.

Conclusions: A unique point in this patient was the absence of any history or current conditions such as bladder outlet obstruction or foreign body, which might predispose bladder to stone formation. Another unique point was the heavy weight ( $826 \mathrm{~g}$ ) of one-piece-stone filling all bladder space. In majority of reported bladder stones, the weight was lower and the stones were in multiple pieces.
\end{abstract}

Keywords:Bladder; Cystolithotomy; Calculi

\section{Introduction}

Bladder stones are the most common form of lower urinary tract stone and constitute 5\% of all urinary tract stones and $1.5 \%$ of all cases admitted to the urology departments (1). In endemic areas, bladder stones develop in children and are mostly found in the setting of poor nutritional and socioeconomic conditions. In contrary, in nonendemic regions, incidence is higher in adults and is usually accompanied with urinary stasis or foreign bodies. The giant bladder stones are very rare (2). Regarding the characteristics of the stone in our case, our report was the first one in Iran and in the world.

\section{Case Presentation}

The patient was a 35-year-old man with lower urinary tract symptoms who was referred to the Urology Clinic of Imam Reza Hospital. He did not have gross hematuria or obstructive lower urinary tract symptoms. There was no history of medical and surgical disease and drug history including administration of over-the-counter drugs. Digital rectal examination revealed insignificant finding. In the examination of suprapubic area, a hard mass with no attachment to the abdominal wall or pelvic area was detected. In the primary laboratory tests, results of urine culture were negative and creatinine was $106.08 \mu \mathrm{mol} / \mathrm{L}$. In urine analysis, 10/hpf of red blood cells, 2-3/hpf of white blood cells, and few oxalate crystals were found. Ultrasonography showed mild bilateral hydroureteronephrosis, and increased bladder wall thickness, and a single large stone with a diameter of $110 \mathrm{~mm}$. In kidneys, ureters, and bladder x-ray(KUB), a round, homogenous, huge density in the pelvic area with smooth edges and another mass with the same density in the right kidney was seen (Figure 1).

Although the diagnosis of bladder stone was made and we decided to perform open cystolithotomy, cystoscopy was done for rule out of any bladder outlet obstruction (BOO) or urethral strictures. The urethra was normal but introduction of cystoscope into the bladder cavity was impossible due to presence of a huge stone that had occupied all the bladder space. Open cystolithotomy was performed using a midline suprapubic incision and a vertical bladder incision. The size of stone resulted in entrapment and inability to extract the stone by common vesical incisions; therefore, we extended the bladder incision into the posterior bladder wall. The bladder stone weighed $826 \mathrm{~g}$ and a dimension of $13 \times 10 \times 8 \mathrm{~cm}$ (Figures 2 and 3). The thick bladder wall was sutured in three layers and a large bore urethral catheter was placed in the urethra. After seven days, the catheter was removed and subsequently, patient's normal voiding was restored. Stone analysis showed 60\% calcium oxalate and $20 \%$ calcium phosphate. In laboratory serum tests, PTH value was within normal limits (49.5 $\mathrm{ng} / \mathrm{L}$ ); other results were within normal limits: creatinine $70.72 \mu \mathrm{mol} / \mathrm{L}$; uric acid $327.17 \mu \mathrm{mol} / \mathrm{L} ; \mathrm{Na} 138 \mathrm{mmol} / \mathrm{L} ; \mathrm{K} 4.4$ $\mathrm{mmol} / \mathrm{L} ; \mathrm{Cl} 99.3 \mathrm{mmol} / \mathrm{L}, \mathrm{Ca}^{2+} 1.2 \mathrm{mmol} / \mathrm{L}$; total Ca 2.40 $\mathrm{mmol} / \mathrm{L}$; and phosphorous, $0.87 \mathrm{mmol} / \mathrm{L}$. Magnesium, Ca, oxalate, citrate, and protein in 24-hour urine were within normal limits. Results of venous blood gas test was normal ( $\mathrm{pH}, 7.34 ; \mathrm{PCO}_{2}, 5.9 \mathrm{kPa}$; and $\left.\mathrm{HCO}_{3}, 24.5 \mathrm{mmol} / \mathrm{L}\right)$.

Copyright (c) 2014, Nephrology and Urology Research Center. This is an open-access article distributed under the terms of the Creative Commons Attribution-NonCommercial 4.0 International License (http://creativecommons.org/licenses/by-nc/4.0/) which permits copy and redistribute the material just in noncommercial usages, provided the original work is properly cited. 
Farshi A et al.

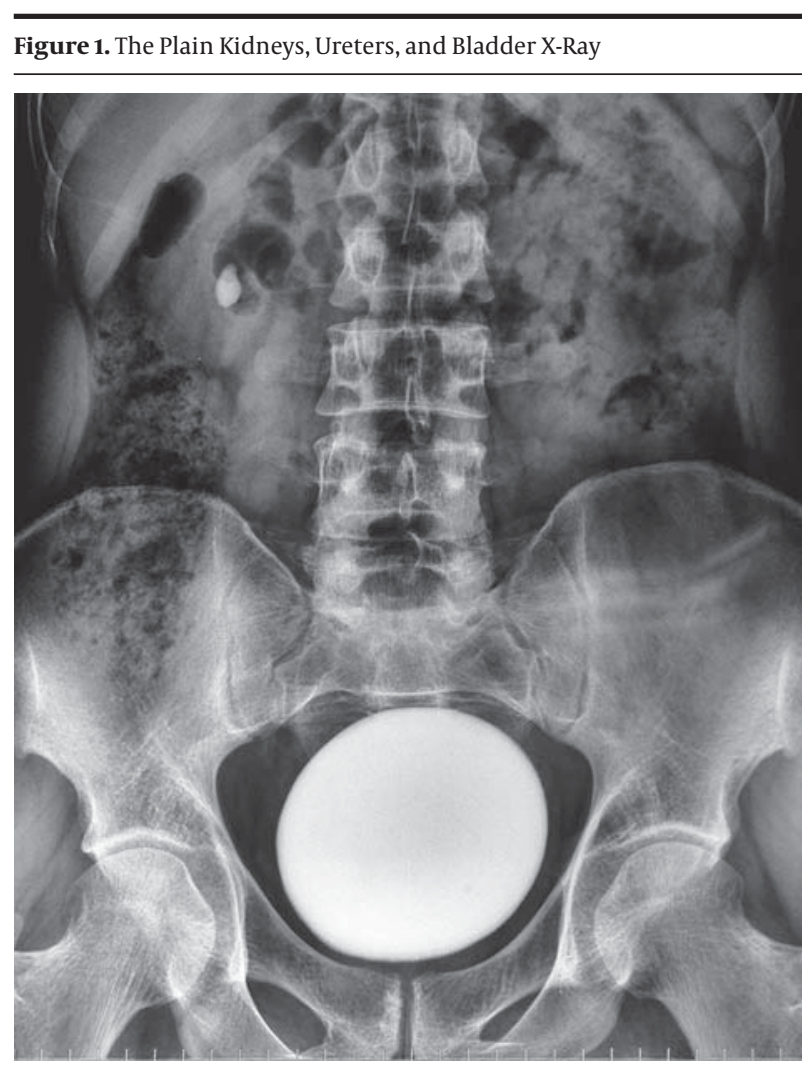

Round homogenous huge density with smooth edge is seen in the bladder.

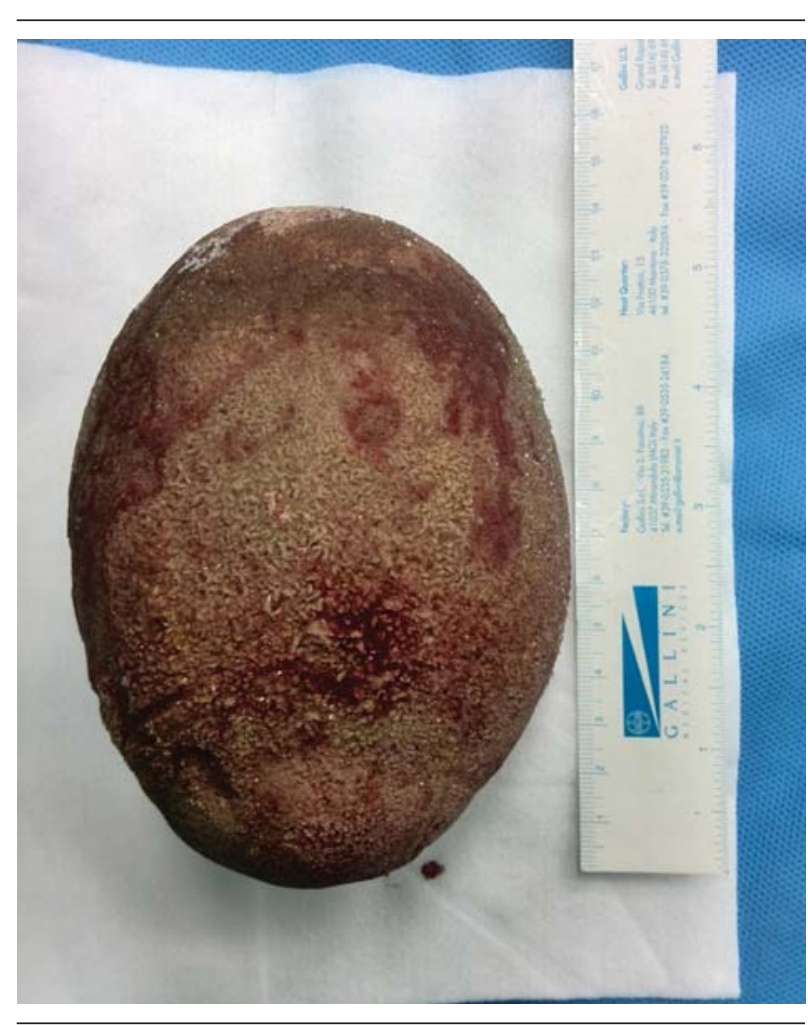

Figure 2. Huge Bladder Stone With Thirteen-Centimeter Length Ten-Centimeter Width

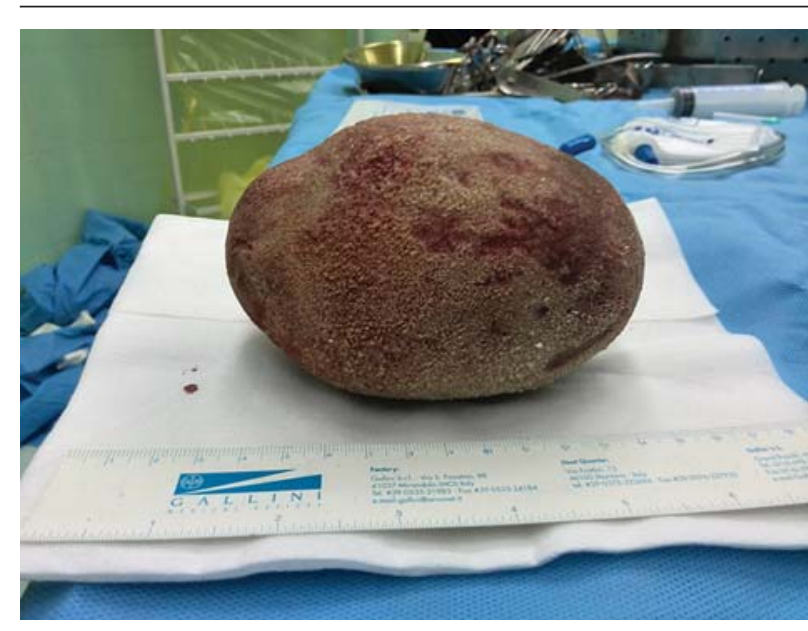

Figure 3. Huge Bladder Stone With Eight-Centimeter Diameter in Lateral View

\section{Conclusions}

Bladder stone is mostly single and multiple stones are seen in only in $25 \%$ to $30 \%$ of cases. These stones are mainly composed of calcium oxalate, calcium phosphate, and ammonium urate. A unique point in our patient was the absence of previous history or current conditions that might predispose him to bladder stone formation such as BOO, urinary tract infection, foreign body, and urologic or pelvic operation. This situation is not compatible with bladder stone epidemiology in Iran as well as industrial countries. Another point was formation of one piece-heavy weight stone that had filled all the bladder space. In majority of reports, the stones were in multiple pieces with lighter weights $(3,4)$. The bladder stone with the same weight was reported from Nigeria; however, the reported patient had BOO as an underlying etiologic factor (5).

Regarding the composition of the bladder stone and the absence of underlying etiologies such as BOO and UTI, two possible factors might be considered for the development of the stone in this patient. Regarding the patient's socioeconomic status and epidemiology of bladder stone in Iran, nutritional problems seemed unlikely in our patient. Metabolic disorders are not among primary and supplementary laboratory tests. For largesized bladder stones, all the reports have recommended open cystolithotomy (2). In a few number of reports the first presentation of bladder stones was acute postrenal failure. Nonetheless, in our patient, mild bilateral hydroureteronephrosis was found on ultrasonographic study and serum creatinine was within normal limits (6-8).

\section{References}

1. Wein AJ, Kavoussi LR, Novick AC, Partin AW, Peters CA. CampbellWalsh Urology: Saunders; 2011.

2. Gallego Vilar D, Beltran Persiva J, Perez Mestre M, Povo Martin IJ, Miralles Aguado J, Garau Perello C, et al. Giant bladder 
lithiasis: case report and bibliographic review. Arch Esp Urol. 2011;64(4):383-7.

3. Komori K, Iwasaki A, Ikegami M, Kajikawa J, Kishimoto T. [Giant bladder stone: a case report]. Hinyokika Kiyo. 2000;46(1):37-40.

4. Aydogdu O, Telli O, Burgu B, Beduk Y. Infravesical obstruction results as giant bladder calculi. Can Urol Assoc J. 2011;5(4):E77-8.

5. Aliyu S, Ali N, Ibrahim AG. Giant vesical calculus. Niger J Med.
2013;22(2):148-50.

6. Komeya M, Sahoda T, Sugiura S, Sawada T, Kitami K. A huge bladder calculus causing acute renal failure. Urolithiasis. 2013;41(1):85-7.

7. Lai AY, Kuo YC. A huge pelvic calculus causing acute renal failure. Am JEmerg Med. 2008;26(2):246 e3-4.

8. Wei W, Wang J. A huge bladder calculus causing acute renal failure. Urol Res. 2010;38(4):231-2. 